Ministerstwo Nauki

i Szkolnictwa Wyższego

Digitalizacja archiwalnych numerów czasopisma naukowego Analecta Cracoviensia 1-24 (1969-1992) i ich publikacja w otwartym dostępie - zadanie finansowane w ramach umowy 672/P-DUN/2017 ze środków Ministra Nauki i Szkolnictwa Wyższego przeznaczonych na działalność upowszechniającą naukę

Ks. JERZY CHMIEL

\title{
TRADYCJA APOSTOLSKA A REDAKCJA ŁUKASZA W DZIEJACH APOSTOLSKICH
}

Wśród 24 mów, które Łukasz umieścił w Dziejach Apostolskich, większość z nich została włożona w usta Apostołów (Piotr, Jakub, Paweł). Powstaje pytanie, czy owe mowy, które możemy nazwać apostolskimi, odzwierciedlają pierwotne nauczanie apostolskie czy też są wyrazem teologii Łukaszowej. Problem ten jest już od dawna dyskutowany i posiada bogatą literaturę ${ }^{1}$. Zamiarem naszym nie będzie wchodzić w szczegóły dyskusji, która $\mathrm{w}$ istocie nie została jeszcze zakończona, lecz przypomniawszy status quaestionis podać racje, dla których należy opowiedzieć się za pierwotną tradycją apostolską wyrażoną w mowach Dziejów.

\section{STAN BADAÑ NAD REDAKTIONSGESCHICHTE W DZIEJACH}

Odnośnie do redakcji mów apostolskich w Dziejach zarysowują się grosso modo dwie opinie ${ }^{2}$.

Pierwsza opowiadając się za kompozycją Łukaszową mów podkreśla jednocześnie, że odzwierciedlają one pierwotny charakter przepowiadania apostolskiego. Opinia ta zyskała wielu zwolenników tak wśród egzegetów protestanckich, z których grona wyszła (M. Kähler, C. C. Torrey, A. von Harnack, M. Dibelius, C. H. Dood, M. Goguel, E. Stauffer, O. Cullmann, O. Bauernfeind, H. W. Beyer, E. Schweizer, B. Reicke, F. F. Bruce, C. S. C. Williams), jak i katolickich (J. Gewiess, L. Cerfaux, J. R. Geisel-

1 Por. informator bibliograficzny A. J. Mattill - Mr. Bedford-Mattill, A Classified Bibliography of Literature of the Acts of the Apostles (NT Tools and Studies 7), Leiden 1966. Stan badań i obszerna bibliografia zostały przedstawione przez J. Dupont, Les sources du Livre des Actes. Etat de la question, Paris-Bruges 1960. Praca została uzupełniona w: tenże, Etudes sur les Actes des Apôtres (Lectio divina 45), Paris 1967. (Angielski przekład: The Sources of Acts, London 1964). Por. również: W. W. Gasque, A History of the Criticism of the Acts of the Apostles (Beiträge zur. Geschichte der bibl. Exegese 17), Tübingen 1974. E. Rasco, La Teología de Lucas: Origen, Desarrollo, Orientaciones (Anal. Greg. 201), Roma 1976 (non vidi!).

2 Zob. J. Dupont, Etudes, 41-50, 134-137. 
mann, J. Schmitt, E. Schick, K. H. Schelkle, J. Dupont, B. Rigaux). Praca M. Dibeliusa (1944) zasługuje na specjalne wyróżnienie z racji uwzględnienia modelu starożytnej historiografii greckiej ${ }^{3}$. Godną uwagi jest monografia J. Schmitta (1949) ${ }^{4}$; posługuje się w niej autor swoistą terminologią: mowy nazywa sommaires, natomiast kerygmat traktuje jako catechèse. Mocno akcentuje wartość typiczną mów odbijających pierwotną katechezę apostolską. Jakkolwiek wiele utrzymywanych przez J. Schmitta tez straciło już na swej aktualności z powodu nowych perspektyw otworzonych przez nowe metody badawcze, jak Redaktionsgeschichte, to jednak zasadnicza teza pracy: mowy w Dziejach świadczą o najstarszej tradycji apostolskiej - pozostaje ciągle w polu zainteresowań egzegetycznych.

Jako reakcja na dopiero co przedstawioną opinię wytworzył się pogląd utrzymujący, że mowy w Dziejach są tylko wyrazem teologii Łukaszowej. Być może, była to reakcja na zbyt drobiazgową Quellenkritik, a także niewątpliwy wpływ metody historii redakcji (Redaktionsgeschichte). Wśród zwolenników tej opinii (Ph. Vielhauer, H. Conzelmann, C. F. Evans, F. C. Grant, D. E. Nineham) wybijają się na czoło E. Haenchen (1956) i U. Wilckens (1961).

W swoim bogatym komentarzu E. Haenchen ${ }^{5}$ poświęca dużo miejsca mowom apostolskim; uważa je za konstrukcję Łukaszową, który chcąc przedstawić główne prawdy przepowiadania chrześcijańskiego rozbił ją na poszczególne mowy. Nie wahał się przy tym Łukasz przypisać ich Piotrowi i Pawłowi, co miało być wyrazem świadomości tożsamości nauczania apostolskiego z Łukaszowym. Terminologia zapożyczona z Septuaginty była - wedle naszego komentatora - pastiszem staroży tności.

Gdy zważy się w całości argumentację Haenchena, nie trudno zauważyć pewne aprioryzmy, podyktowane zresztą tendencją pokazania systemu teologicznego autora Dziejów Apostolskich. Nic przeto dziwnego, że J. Dupont nie jest bynajmniej przekonany o słuszności argumentacji Haenchena ${ }^{6}$, co też $\mathrm{w}$ całości podzielamy.

Przejdźmy teraz do najpoważniejszej w ostatnich latach monografii U. Wilckensa na temat mów apostolskich ${ }^{7}$. Autor dochođzi do przekona-

3 I. Dibelius, Die Reden der Apostolgeschichte und die antike Geschichtsschreibung, w: Aufsätze zur Apostelgeschichte, wyd. H. Greeven, Göttingen ${ }^{3} 1957,120$-262 (Angielskie wydanie: Studies in the Acts of the Apostles, ed. by H. Greeven, London '1973, 138-185). Pracę Dibeliusa zanalizował J. Dupont, Etudes, 47-50.

4 J. Schmitt, Jésus ressuscité dans la prédication apostolique. Etude de théologie biblique, Paris 1949. Por. uwagi J. Duponta, Etudes, 44-47.

5 E. Haenchen, Die Apostelgeschichte (Kritisch-exegetischer Kommentar NT 3), Göttingen ${ }^{10} 1956$. J. Dupont dając obszerną recenzję tego komentarza (Etudes, 125131), nazywa go "un important commentaire du livre des Actes."

6 J. Dupont, Etudes, 128.

7 U. Wilckens, Die Missionsreden der Apostelgeschichte. Form und Traditionsgeschichtliche Untersuchungen (WMANT 5), Neukirchen 1961. 
nia, że plan wszystkich mów jest identyczny: dłuższe mowy zawierają sześć elementów. Nie ma potrzeby szukania dawnych tradycji, mowy są produktem teologicznym Łukasza. Niemniej jednak Wilckens stosując metodę historii form i historii tradycji (jak zapowiada podtytuł jego pracy: Form- und Traditionsgeschichtliche Untersuchungen ${ }^{8}{ }^{8}$ nie jest wolny od niekonsekwencji, skoro $\mathrm{z}$ jednej strony wzbrania się przed przyjęciem warstw tradycji w mowach zredagowanych przez Łukasza, a z drugiej analizując teologię zmartwychwstania Jezusa ${ }^{9}$ zwraca uwagę na stare, tradycyjne formuły kerygmatyczne. Toteż tezy Wilckensa zostały przyjęte dość krytycznie, jakkolwiek praca jego jest użytecznym narzędziem poszukiwań egzegetycznych ${ }^{10}$.

Wydaje się, że istnieją poważne racje, ażeby przyjąć, iż w mowach apostolskich odbija się pierwotna tradycja Kościoła, a nie tylko koncepcja teologiczna autora Dziejów. Już w latach trzydziestych M. Goguel pisał: „można znaleźć w Dziejach Apostolskich pewne dane, które oddają dość wiernie koncepcję zmartwychwstania Jezusa, która nawet jeśli nie jest bezwzględnie pierwotna, to jest w każdym razie najstarsza, do jakiej jesteśmy w stanie dojść bezpośrednio" 11. Do owych danych należą - sądzę - cytaty starotestamentalne, których użycie i interpretacja musi sięgać najstarszych warstw przepowiadania chrześcijańskiego ${ }^{12}$.

\section{CYTATy STAROTESTAMENTALNE A RECENZJE TEKSTU}

L. Cerfaux ${ }^{13}$ wyodrębnil dwa rodzaje cytatów: $1^{\circ}$ cytaty proste, w zasadzie wiernie oddające tekst LXX; $2^{\circ}$ cytaty seryjne („en serie”), gdzie różnice $\mathrm{w}$ porównaniu $\mathrm{z}$ tekstem LXX rzucają się $\mathrm{w}$ oczy. W tym wypadku autor Dziejów posługiwałby się nie tekstem biblijnym, lecz zbiorem cytatów (catena), będących do dyspozycji mówców.

Wnikliwą analizę użycia tekstów ST w mowach apostolskich przeprowadził J. Dupont 14. Wykazując niekompletność cytatów pragnie Dupont w ten sposób wskazać na działalność redakcyjną Łukasza.

s Jak zauważa J. Dupont (Etudes, 134, przyp. 4), Wilckens był pod wpływem badań H. Conzelmanna nad trzecią ewangelią (Die Mitte der Zeit, 1 wyd. 1954).

9 Die Missionsreden, 137-149.

10 Zob. uwagi krytyczne J. Duponta, Etudes, 133-155, jak również B. Rigaux, Dieu l'a ressuscité. Exégèse et théologie biblique, Gembloux 1973, $57 \mathrm{n}$.

11 M. Goguel, La foi à la résurrection de Jésus dans le christianisme primitif, Paris 1933, 19.

12 Zająłem się tym sżczegółowo w pracy: Interpretacja Starego Testamentu $w$ kerygmacie apostolskim o zmartwychwstaniu Jezusa. Studium hermeneutyczne, Kraków 1975 (maszynopis).

${ }_{13}$ L. Cerfaux, Citations scripturaires et tradition textuelle dans le Livre des Actes, w: Aux sources de la tradition chrétienne. Mélanges offerts à $M$. Maurice Goguel, Neuchâtel-Paris 1950, 43-51. Zob. także: tenże, L'exégése de l'Ancien Testament par le Nouveau Testament, w: L'Ancien Testament et les chrétiens (Rencontres 36), Paris 1951, 139.

14 Etudes, 245-282. 
Wydaje mi się to dość nieprzekonywujące: u podstaw bowiem owej niekompletności cytatów może znajdować się nie ten czy ów retusz redakcyjny Łukasza, lecz sposób argumentacji pierwszych głosicieli Dobrej Nowiny. Istotnie, Dupont dochodzi później do określenia cech charakterystycznych egzegezy stosowanej $\mathrm{w}$ mowach apostolskich. Jest to więc najpierw egzegeza oparta na dosłowności pewnych wyrażeń (,„à la lettre du texte"), lecz niemniej mesjańska w głębokich wymiarach teolngicznych. Zatem już przed pracą redakcyjną Łukasza mielibyśmy do czynienia z pewnym określonym typem argumentacji teologicznej, opartej na rabinistycznym sposobie myślenia i dowodzenia, co wszakże nie przekreśla pewnych retuszów redaktora mów. Ośmielam się tylko twierdzić, że Łukasz w swym redagowaniu tekstów nie posunął się aż tak daleko, ażeby zniweczyć schemat argumentacji, jaki przejął z pierwotnego przepowiadania.

J. Dupont kilkakrotnie podkreśla, że cały ciężar dowodzenia opiēra się na greckiej wersji tekstów starotestamentalnych. Jeżeli mowy mają zdradzać pierwotny charakter przepowiadania chrześcijańskiego, to w jaki sposób pogodzić ich grecką wersję z aramejskim podkładem? J. Dupont jest zbyt doświadczonym maître d'exégèse, by widzieć Łukasza tłumaczącego na grecki kazanie aramejskie przy pomocy tekstu Septuaginty! Wobec tego wysuwa przypuszczenie, że „,mowy Dziejów przedstawiają przepowiadanie apostolskie nie w swoim początkowym aramejskim stadium, lecz $\mathrm{w}$ drugim stađium - hellenistycznym, które również sięga pierwszych lat Kościoła jako frakc:a wspólnoty jerozolimskiej posługująca się greczyzną. Nie można przecież lekceważyć tej frakcji, która miała na czele siedmiu diakonów i która dała początek wielkiemu ruchowi misjonarskiemu w okresie apostolskim. Należy także przypuścić, że przepowiadanie chrześcijańskie w środowisku hellenistycznym było wiernym odbiciem przepowiadania aramejskiego dokonywującego się u „Hebrajczyków”. Ta wierność nie musiała być zwykłym powtarzaniem; na Biblii greckiej dokonywano takich zabiegów, których ze swej strony dokonywali „Hebrajczycy” na Biblii hebrajskiej lub na jej tłumaczeniu aramejskim" ${ }^{15}$.

Propozycja jest kusząca, tylko owo „wierne odbicie” trzeba przyjąć na słowo honoru.

Ostatnie prace na temat cytatów starotestamentalnych $\mathrm{w}$ mowach Dziejów Apostolskich nie wnoszą nic nowego. Zwracają uwagę analizy M. Wilcoxa (1965), który podkreśla, że wiele cytatów ST odbiega od wersji LXX, by iść za TM lub targumami ${ }^{16}$. T. Holtz (1968) nie wy-

15 Tamże, 273 n.

16 M. Wilcox, The Semitisms of Acts, Oxford 1965. J. Dupont (Etudes, 285, przyp. 8) krytycznie ocenia analizy Wilcoxa. Nie uwzględnia jednak jego - tu 
chodzi poza wskazanie żródeł cytatów podkreślając ich dobór z tekstu Septuaginty ${ }^{17}$, natomiast M. Rese (1969) poświęca się w zupełności badaniu motywów ${ }^{18}$.

Mówiąc o cytowanych w Dziejach tekstach ST nie sposób pominąć szeroko dyskutowanej kwestii recenzji tekstualnych Dziejów ${ }^{19}$. Kiedyś L. Cerfaux próbował znaleźć równowagę pomiędzy recenzją B (wschodnią) a D (zachodnią), przyznając jednak tej pierwszej pewną troskę o wierność cytowania z Septuaginty. Niemniej tekst D jest starszy od B; ten pierwszy pochodzi z czasów kolekcji ksiąg, ten drugi jest wynikiem recenzji uczonych z wieku III-IV w Aleksandrii ${ }^{20}$.

$\mathrm{Na}$ wartość recenzji zachodniej (D) wskazuje również J. Dupont, dla którego dwie recenzje D i B są świadkami dwóch etapów ustalenia tekstu: D przedstawia więc etap źródeł użytych przez Łukasza, podczas gdy B wyraża stan redakcji tekstu ${ }^{21}$. Ogólnie mówiąc - egzegeci faworyzują tekst $\mathrm{D}$, jakkolwiek nie są $\mathrm{W}$ stanie podać przekonywujących argumentów.

Ostatnie badania krytyki tekstualnej przyniosły jednak pewne zmiany - nie na tyle co prawda, ażeby rozstrzygnąc definitywnie priorytet którejkolwiek recenzji, lecz wystarczająco, ażeby zmienić postawę badawczą. C. M. Martini (1966) na podstawie wielu przykładów udowodnił, $\dot{z}$ e po publikacji papirusu Bodmer XIV—XV (P $\left.{ }^{75}\right)$ nie jest rzeczą możliwą mówić o recenzji, jakiej zostałby poddany tekst trzeciej ewangelii w B w wieku III lub IV. Podnkieństwa bowiem pomiędzy B a $\mathrm{P}^{75}$, nawet w najdrobniejszych szczegółach, ¿ie mogą być przypadkowe. Należy przeto przyjąć pokrewieństwo genealogiczne pomiędzy $\mathrm{P}^{75}$ a $\mathrm{B}$. Tekst wschodni (B) przedstawia starożytną tradycję sięgającą roku 200, a nawet nieco wcześniej, zważywszy fakt, że $\mathrm{P}^{75}$ i $\mathrm{B}$ nie mają bezpośredniego odniesienia genealogicznego, lecz czerpią swoje podobieństwo z jakiegoś archetypu wcześniejszego ${ }^{22}$.

cytowanego - dzieła, lecz o wiele wcześniejszy artykuł. Nie przesądzając sprawy wydaje się, iż trzeba więcej uwagi poświęcić sugestiom Wilcoxa.

${ }_{17}$ T. Holtz, Untersuchungen über die altestamentlichen Zitate bei Lukas (TU 104), Berlin 1968.

18 M. Rese, Alttestamentliche Motive in der Christologie des Lukas (Studien zum NT 1), Gütersloh 1969. Por. D. M. Smith, The Use of the Old Testament in the New, w: The Use of the Old Testament in the New and Other Essays. Studies in Honour of W. F. Stinespring, ed. by J. M. Efird, Durham 1972, 3-65, gdzie znajduje się Forschungsbericht począwszy od $1945 \mathrm{r}$.

19 Omawia to szczegółowo J. Dupont, Etudes, 24-32.

20 L. Cerfaux, Citations scripturaires, 51. Por. A. F. J. Klijn, A Survey of the Researches into the Western Text of the Gospels and Acts. Part 2: 1949-1969 (Suppl NT 21), Leiden 1969. J. Duplacy, $A$ propos d'une variante occidentale des Actes des Apôtres (III, 11), „Revue des études augustiniennes” (Mémorial G. Bardy), 2 (1956) 231-244.

21 J. Dupont, Etudes, 30.

22 C. M. Martini, Il problema della recensionalità del codice $B$ alla luce del papiro Bodmer XIV (Anal. Bibl. 26), Roma 1966. Tenże, I papiri Bodmer e $i$ nuovi 
Odnośnie do tekstu cytatów w mowach apostolskich Dziejów nasuwa się wniosek praktyczny. Nie można uogólniać, lecz każdy poszczególny wypadek należy badać osobno. Należy powstrzymać się od dawania pierwszeństwa którejkolwiek recenzji w ogóle. Decyzja wyboru wariantu winna zależeć od kontekstu, od typu argumentacji i od pewnej concordia discordans.

\section{PROPOZYCJE}

Nie wchodząc w szczegóły ciągle otwartej dyskusji na temat historii redakcji Dziejów Apostolskich, można zgodzić się co do następujących stwierdzeń:

3.1. Mowy apostolskie w swojej strukturze redakcyjnej są dziełem Łukasza, ale trudno nie przypuścić, ażeby w redagowaniu nie posłużył się on archaicznym materiałem kerygmatycznym, skoro zaangażował autorytety Apostołów, a zwłaszcza Piotra ${ }^{23}$.

3.2. W naszym zagadnieniu nie jest najważniejsze pytanie, do jakiego stopnia mowy zostały wygłoszone w takiej formie, w jakiej zostały spisane. Dotychczasowe badania metodą historii redakcji (Redaktionsgeschichtliche Methode) skłaniają raczej do porzucenia hipotezy zapisu względnie streszczenia mów faktycznie wygłoszonych. Niemniej jednak zadaniem metody historii redakcji jest „wyłuskanie” najstarszych formuł kerygmatycznych, które w specyficznym Sitz im Leben zostały wkomponowane $\mathrm{w}$ większe całości. Stąd istotnym będzie takie postawienie problemu, które pozwoli na uchwycenie $\mathrm{schematów} \mathrm{argu-}$ mentacyjnych opartych na terminologii i podstawowych formulach stanowiących trzon kerygmatu ${ }^{24}$.

3.3. Na odzwierciedlenie tradycji apostolskiej w mowach Dziejów mogą wskazywać loci scripturistici; są one osnową całej argumentacji przemówień. Cytaty świadczą o teologii ${ }^{25}$.

\footnotetext{
orientamenti della critica testuale del $N$. T., w: Il Messianismo. Atti della XVIII Settimana Biblica, Brescia 1966, 357-367.

${ }_{23}$ J. Dupont, Les discours de Pierre dans les Actes et le chapitre XXIV de l'évangile de Luc, w: F. Neirynck (red.), L'Evangile de Luc. Problèmes littéraires et théologiques. Mémorial L. Cerfaux, Gembloux 1973, 329-374, zwraca uwagę na autorytet Piotra w I części Dziejów Apostolskich. Mowy Piotra są wyrazem wszystkich Apostołów. Warto przypomnieć używanie przez Łukasza terminu ,apostoł" zawsze $\mathrm{w}$ pluralis, nigdy $\mathrm{w}$ singularis $(6 \times \mathrm{w} \notin \mathrm{k}, 28 \times \mathrm{w} \mathrm{Dz})$. Na rolę teologii Piotra w Dziejach zwracał już uwagę E. Trocmé, Le „Livre des Actes” et l'histoire, Paris $1957,210 \mathrm{n}$.

24 Analizę schematów argumentacyjnych odnośnie do kerygmatu apostolskiego o zmartwychwstaniu Jezusa podjąłem w cytowanej już pracy o interpretacji ST (zob. przyp. 12).

${ }_{25}$ "Les citations révèlent une théologie" - spostrzeżenie B. Rigaux (Dieu l'a ressuscité, 60), które urasta do rangi zasady.
} 


\section{LA TRADITION APOSTOLIQUE ET LA RÉDACTION DE LUC DANS LES ACTES DES APÔTRES}

\section{R E S U M E}

Le propos de l'auteur est d'examiner la question: est-ce que les discours dans les Actes, dits apostoliques, reflètent une tradition primitive de la prédication apostolique ou bien sont-ils élaboration de la théologie de Luc.

1. D'abord les deux opinions d'exégètes sont présentées. Les uns, tant protestants que catholiques, ont voulu voir dans les discours une prédication apostolique. Il faut mentionner, d'une manière spéciale, les ouvrages de M. Dibelius et J. Schmitt. Pour d'autres, les discours sont des compositions lucaniennes, mais cette position n'est pas celle de nombreux exégètes. Les deux en sont particulièrement examinés: E. Haenchen et U. Wilckens. L'auter même se rallie plutôt à l'opinion que les discours apostoliques des Actes reflètent la tradition apostolique de l'Eglise primitive.

2. Ensuite l'auteur consacre son attention à des citations de l'Ancien Testament qui jouent un rôle important dans les Actes. „Les citations révèlent une théologie” (B. Rigaux). La relation du texte massorétique et de la Septante et la comparaison des citations des Actes, avec l'un et l'autre s'imposent. On aborde la question des deux textes des Actes, c'est-à-dire la récension dite orientale (B), et la récension dite occidentale (D). Les résultats des recherches de C. M. Martini sont mentionnés, c'est-à-dire la valeur de la récension $\mathrm{B}$.

3. Enfin, quelques propositions sont à considérer:

3.1. C'est Luc qui a rédigé les discours, mais il fait appel à des matériaux anciens du kérygme apostolique.

3.2. Il ne s'agit pas non plus de la forme des discours: qu'ils furent prononcés tels qu'ils sont, mais il faut dégager, à la lumière d'une saine méthode de l'histoire de la rédaction, des s chémas d'argumenta tion de la tradition apostolique, qui se trouvent dans les discours.

3.3. Il faut prendre en considération les citations scripturaires. 